\title{
Yellow Warblers (Setophaga petechia) Rear Second Broods in Some Years at Delta Marsh, Manitoba
}

\author{
SPENCER G. SEALY \\ Department of Biological Sciences, University of Manitoba, Winnipeg, Manitoba R3T 2N2 Canada; email: sgsealy@cc.uman \\ itoba.ca
}

Sealy, Spencer G. 2014. Yellow Warblers (Setophaga petechia) rear second broods in some years at Delta Marsh, Manitoba. Canadian Field-Naturalist 128(1): 44-49.

Twenty cases of double brooding by colour-marked Yellow Warblers (Setophaga petechia) were recorded in 5 of 11 years (1975-1986, no data collected in 1977) during studies of breeding ecology in the dune-ridge forest at Delta Marsh, Manitoba (1 pair in 1975, 3 pairs in 1976, 3 pairs in 1984, 9 pairs in 1985, and 4 pairs in 1986). At least one member of each of the 20 pairs was marked. Eleven pairs re-used their first nest for the second attempt, whereas 9 females built a new nest, in 5 cases because the original nests had disintegrated. Four of the second nests (3 in 1985 and 1 in 1986) were parasitized by Brown-headed Cowbirds (Molothrus ater). All 20 first nests produced at least one young, a condition for double brooding, and 13 second nests, including 3 that were parasitized, were successful. Failure of about $60 \%$ of annual nesting attempts at Delta Marsh may contribute to the low number of pairs with double broods recorded in some years and the absence of double brooding in years of comparable phenology. This is the first published evidence of double brooding in the Yellow Warbler.

Key Words: double broods; Yellow Warbler; Setophaga petechia; Delta Marsh; Manitoba

\section{Introduction}

Knowledge of the number and success of broods attempted by birds in each breeding season is important for an understanding of the dynamics of avian populations and life history evolution (Martin 1987). One of the components of the life cycle is the number of broods individuals typically rear in each breeding season, whether one, two or even more in certain years when conditions are suitable. This contrasts with the replacement of clutches and broods that may be depredated or otherwise fail, possibly due to inclement weather.

An irrefutable determination that birds have raised one brood and attempted to raise another requires careful monitoring of colour-marked individuals or radiotracking throughout the entire breeding season. In some species, researchers have recorded double brooding infrequently, often as isolated cases (e.g., in the Northern Yellow-throat, Geothlypis trichas (Stewart 1953); in Kirtland's Warbler, Setophaga kirtlandii (Radabaugh 1971); in the Bobolink, Dolichonyx oryzivorus (Gavin 1984); and in the Dickcissel, Spiza americana (Bolinger and Maddox 2000)), whereas others have recorded double brooding by $6-48 \%$ of pairs, with successful second broods increasing an individual's annual productivity (e.g., in the Black-throated Blue Warbler, Setophaga caerulescens (Holmes et al. 1992); in the Hooded Warbler, Setophaga citrina (Evans Ogden and Stutchbury 1996); and in the Louisiana Waterthrush, Parkesia motacilla (Mulvihill et al. 2009)).

During an 11-year study of breeding and feeding ecology of Yellow Warblers (Setophaga petechia) in a riparian habitat at Delta Marsh, Manitoba, from 1975 to 1986 (no data were collected in 1977), co-workers and I recorded irrefutable evidence of the rearing of second broods after young had fledged from first nests, but only in some years. Other workers have suspected double brooding by Yellow Warblers, but their observations were based on one or only a few nests attended by unmarked birds (e.g., Stoner 1932; Salt 1973; Bancroft 1979). Confirmation of double brooding by Yellow Warblers at the northern latitude of Delta Marsh suggests that double brooding may be a regular occurrence in this species' breeding biology.

\section{Study Area}

Data from first and second broods of the Yellow Warbler were recorded from nests discovered in the dune-ridge forest that separates Lake Manitoba and Delta Marsh, Manitoba, 50 $11^{\circ} \mathrm{N}, 98^{\circ} 19^{\prime} \mathrm{W}$ (Goossen and Sealy 1982; MacKenzie 1982; MacKenzie et al. 1982; Pohajdak 1988). Nests were monitored over 11 years (1975-1986, except 1977) by J. P. Goossen (1975 and 1976) and by me in the other years, although some nests in the latter years were located by co-workers conducting other studies. The number of Yellow Warbler nests, which included replacement nests, monitored in each year of the study was: 119 in 1975, 148 in 1976, 64 in 1978, 59 in 1979, 44 in 1980, 126 in 1981, 157 in 1982, 237 in 1983, 260 nests in 1984, 225 in 1985, and 241 in 1986.

Yellow Warblers investigated in this study nested in a 7-km portion of the dune-ridge forest ( $\sim 80 \mathrm{~m}$ wide; $56 \mathrm{ha}$ ), abutted by the lake on the north side and an extensive marsh of cattail (Typha latifolia) and reed (Phragmites communis) on the other (see map in Sealy 1980a). This portion of the ridge forest stretched from the west at Cram Creek eastward along the property of the Portage Country Club to the eastern edge of the property of the Delta Marsh Field Station (University of Manitoba). Yellow Warblers nested in the ridge for- 
est predominantly in Sandbar Willow (Salix interior), Manitoba Maple (Acer negundo), Red-berried Elder (Sambucus pubens), Pin Cherry (Prunus pensylvanica), Choke Cherry (P. virginiana), and Red-osier Dogwood (Cornus stolinifera). Peach-leaved Willow (S. amygdaloides), Green Ash (Fraxinux pennsylvanica), and Eastern Cottonwood (Populus deltoides) also contributed to the overstory vegetation in this riparian habitat, but few Yellows Warblers nested in them (MacKenzie et al. 1982).

\section{Methods}

Adults of this sexually dichromatic, seasonally monogamous species (Reid and Sealy 1986) were mistnetted and colour-marked as after-hatch-year (AHY) males or females, following an annual banding protocol established late in 1974 and continued in each subsequent year of the study (e.g., Sealy 1980b; Sealy and Biermann 1983). Thus the first spring in which marked individuals were present in the study area was in 1975 .

In addition, males and females were opportunistically captured and colour-banded near their nests (Cosens and Sealy 1986; Hobson and Sealy 1989). Colourmarking of nestlings and hatch-year (HY) individuals mist-netted prior to fall migration also began in 1975, and birds marked in that and subsequent years resulted in individuals of known age present in the study area in successive years. These individuals originally received a single coloured band, which, in combination with an aluminum band, denoted the year of hatch, so these birds became recognizable in their first spring as secondyear (SY) individuals, and older in succeeding years. Upon recapture, year-marked individuals received two additional coloured bands that uniquely identified them. This marking program resulted in a sample of nests each year that were attended by at least one marked male or female (in several cases both adults were marked).

Yellow Warblers nested at densities up to 29 pairs/ha in the ridge forest in those years (Goossen and Sealy 1982; also see Sealy 1995). This density allowed dozens of nests to be discovered in most years before clutches were initiated, enabling day-to-day inspections as eggs were laid and inspections every one to four days through fledging of first and second broods. The extremely high nesting densities (Goossen and Sealy 1982), however, meant that only a small undetermined number of individuals could be marked, thus precluding the determination of the proportion of pairs that attempted second broods in each of the years in which double brooding was recorded.

I am confident that second broods were not attempted by any pairs in the 6 years in which none were recorded because I monitored a sample of nests, both those attended by marked birds and those attended by unmarked birds, equally diligently throughout all breeding seasons of the study (see Sealy 1995; Guigueno and Sealy 2010; Mazarolle et al. 2011).

\section{Results}

Double brooding was recorded in 20 pairs of Yellow Warblers of known age in 5 of the 11 years of the study (Table 1): 1975 ( $n=1$ pair), 1976 ( $n=3$ pairs), 1984 ( $n=3$ pairs), 1985 ( $n=9$ pairs), and 1986 ( $n=4$ pairs). At least one member of each pair was marked. Males (at 8 nests), females (at 5 nests), or both males and females (at 7 nests) were marked, thus permitting irrefutable confirmation of double brooding (Table 1).

These data suggest that all pairs remained together during the second nesting attempt, although polygyny, albeit infrequent in this population (Sealy 1984; Reid and Sealy 1986), could have resulted in a change of mate at nests where only one of the adults was marked. This would not change the fact, however, that double brooding occurred.

Among the 20 pairs with double broods were 4 whose second clutch was parasitized by a Brownheaded Cowbird (Molothrus ater) (3 in 1985 and 1 in 1986). None of the first nests of these or any of the other pairs that went on to attempt to raise a second brood were parasitized (Table 1). The frequency of parasitism by Brown-headed Cowbirds in this population of Yellow Warblers (also see Sealy 1995) was $26.1 \%$ of 119 nests monitored in $1975,23.0 \%$ of 148 nests in $1976,18.1 \%$ of 260 nests in $1984,18.7 \%$ of 225 nests in 1985 , and $17.8 \%$ of 241 nests in 1986 .

Each pair's first nesting attempt successfully fledged at least one young, a necessary condition for double brooding. At one of the first nests in 1985, however, incubation was delayed about 3 days while the female replaced 3 of 4 eggs that had gone missing from the original nest (footnote 3 of Table 1). Clutches at 18 of the 20 first nests $(90 \%)$ were initiated by 2 June (Table 1) in years where first eggs in the population were initiated on or up to 7 days before this date (also see table III in Sealy 1995).

All 7 marked pairs remained together for their second nesting attempt, lending support to the assumption that the members of the other pairs also did not change (although in these cases it was confirmed only that the same marked individuals ( 8 males and $6 \mathrm{fe}-$ males) remained for the second attempt). Eleven pairs, including the 4 pairs whose second clutches were parasitized, used their first nest for the second attempt. One female whose nest had been parasitized built a new nest over top of the one Brown-headed Cowbird and the two Yellow Warbler eggs that had been laid in the original nest. Nine females built a new nest for the second attempt (Table 1), in 5 cases because the original nests had disintegrated. The other 4 pairs built a new nest in another location nearby. None of the individuals with double broods was among the pairs that double brooded in previous or subsequent years, and no young produced in first or second nests, although banded, were subsequently captured in the study area.

Mean dates (nearest day and standard deviation) of initiation of the 20 first and second clutches were 30 


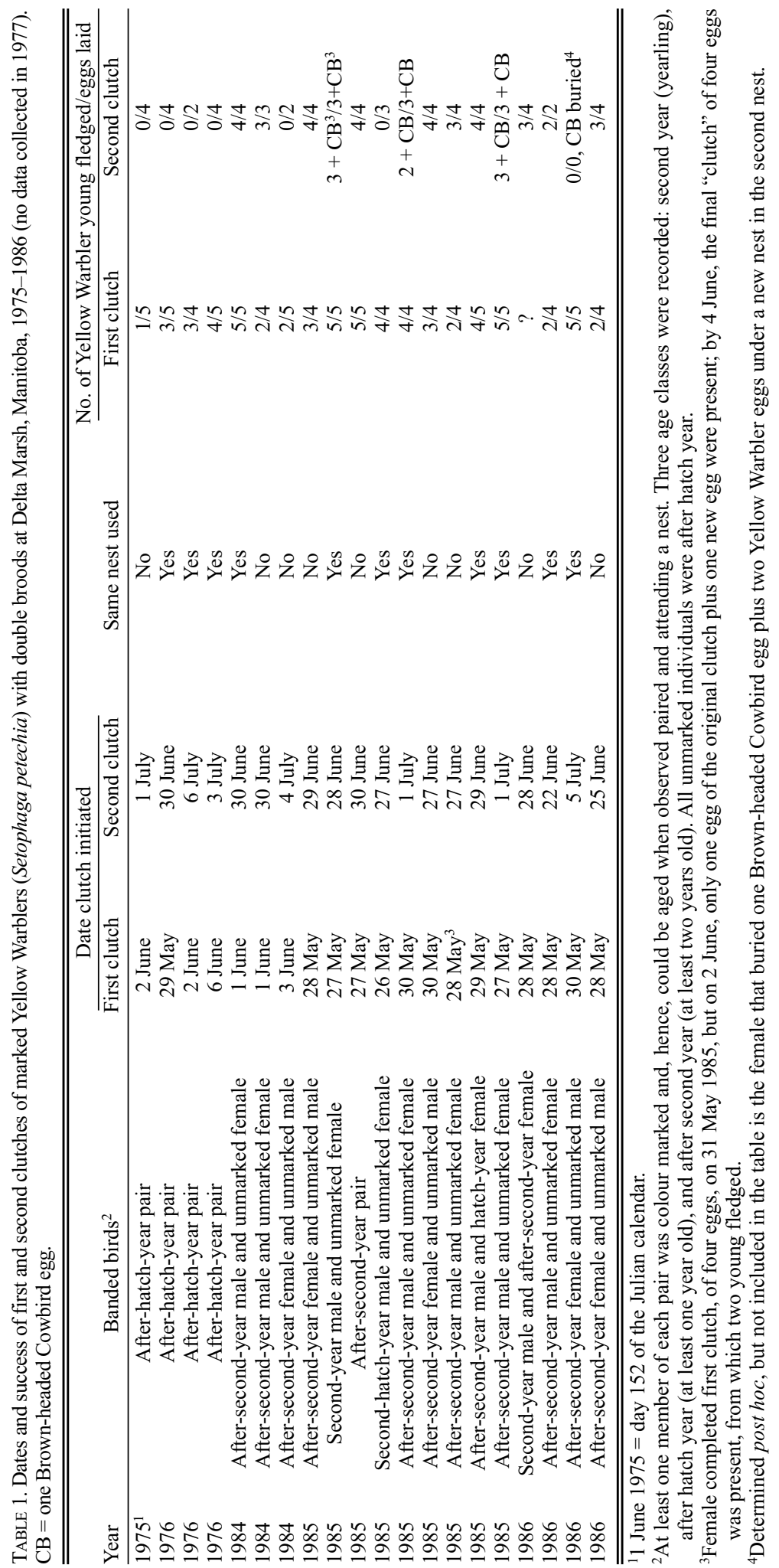


May (SD 2.9 days) and 30 June (SD 3.2 days), respectively, and the mean number of days between initiation of first and second clutches was 30.2 days (SD 2.3 days). Mean initiation of first clutches by females with double broods followed the earliest dates that clutches were initiated in the population within 1 day (1975), 3-9 days (1976), 0-2 days (1984), 0-3 days (1985), and 1-3 days (1986). Initiation of second clutches preceded the last dates of the season for females still attempting to lay clutches by 6 days (1975), 0-7 days (1976), 3-7 days (1984), 7-11 days (1985), and 1-14 days (1986). The mean number of days between dates of fledging of the last nestling from first broods and dates of clutch initiation at unparasitized second nests ( $n=16$ nests) was 3.6 days (SD 1.5 days): 2 days ( $n=2$ nests), 3 days ( 7 nests), 4 days (4 nests), 5 days ( 1 nests), 6 days ( 1 nest), and 8 days ( 1 nest).

Parasitized nests were excluded from this analysis because of possible interference with initiation of the Yellow Warblers' clutches; indeed, a delay of 3 days in the completion of the clutch occurred at one nest parasitized in 1986 (Table 1), in which the Yellow Warbler buried the eggs. This nest eventually failed (see Clark and Robertson (1981) and Guigueno and Sealy (2010) for details of the chronology of laying by Yellow Warblers parasitized by Brown-headed Cowbirds).

\section{Discussion}

\section{Documentation of double brooding}

Data presented in Table 1 provide the first published evidence that Yellow Warblers attempt second broods in some years. Double brooding by Yellow Warblers has not been confirmed elsewhere in North America (but see below), but it has been confirmed in a nonmigratory population on the Galápagos Islands, Ecuador (Snow 1966), located at the equator. Snow recorded a single marked pair that attempted to rear two broods in each of two consecutive years, but in both years the second attempt failed. He added (Snow 1966, page 46) that the "season is amply long enough for [rearing second broods], and two broods are probably common." The fact that double brooding has not been recorded at other sites, tropical or temperate, probably reflects the lack of observations of uniquely marked individuals throughout the breeding season.

These data support an earlier observation of an unmarked pair of Yellow Warblers that suggested double brooding in Manitoba, along the west shore of Lake Winnipeg, in 1978 (Bancroft 1979; also see Gollop 1979). Dates of initiation of the first and second clutches were in line with those presented for Delta Marsh and Lake Manitoba in Table 1. This pair's first nest was under construction on 26 May when it was first observed, and by 2 June it contained two Yellow Warbler eggs. An undetermined number of young had left the nest by 23 June, but by 7 July, the (same?) female was incubating 3 more eggs in the same nest from which the first brood had fledged. Again, an undetermined number of young, in the second brood, fledged by $27 \mathrm{July}$, as noted by feces on foliage near the empty nest and audible vocalizations of fledglings and adults in a nearby hedge (Bancroft 1979). Both adults fed young from the first brood, but it was not reported whether both cared for young in the second brood.

Post-hoc examination of the nest by H. W. R. Copland of the Manitoba Museum in Winnipeg after the second brood had fledged revealed the nest had been parasitized by a Brown-headed Cowbird during the laying of the second clutch, whereupon the Yellow Warbler buried the Brown-headed Cowbird egg plus two of her own eggs, one of which was broken, under a new nest, and started again. The time spent burying the Brown-headed Cowbird egg and her own eggs, reconstructing the nest, and replacing the initial eggs of the second clutch suggests the final clutch was initiated on 28 or 29 June, consistent with the dates of initiation of second clutches at Delta Marsh, including the nest parasitized in 1986 in which the Yellow Warbler buried the Brown-headed Cowbird and her first two eggs (Table 1).

Additional irrefutable records of double brooding by Yellow Warblers came to light during the review of this manuscript. One is in a population nesting at the northern limit of the species' range, near Inuvik, Northwest Territories $\left(68^{\circ} 21^{\prime} \mathrm{N}, 133^{\circ} 45^{\prime} \mathrm{W}\right)$, and the other is near Revelstoke, British Columbia $\left(50^{\circ} 57^{\prime} \mathrm{N}, 118^{\circ} 10^{\prime} \mathrm{W}\right)$ (Anna Drake, personal communication). Near Revelstoke, four cases of double brooding were recorded over eight years at a latitude similar to that of Delta Marsh. In 2004, a second-year female paired with an after-hatch-year male initiated first and second clutches on 25 May and 23 June, respectively. Three young fledged from each clutch. In 2005, two cases involved after-second-year females (one the female with the double brood in 2004 paired with the same male), which initiated first clutches on 27 and 30 May (fledging 5 and 3 young, respectively), and second clutches on 24 and 28 June, respectively (fledging 3 young from each nest). In 2011, an after-second-year female produced a maximum of three fledglings in the first clutch (initiated 30 May) and she produced a second clutch (date of initiation unknown). Dates of initiation of first and second clutches in this population were a few days earlier than those recorded at Delta Marsh (Table 1).

At Inuvik, Drake recorded a marked pair of afterhatch-year individuals that reared two broods in 2010, although the male was not observed while the female tended the second brood. First and second clutches were initiated on 1 June and 1 or 2 July, respectively, and the young fledged on 26 or 27 June and 23 or 24 July, respectively. These dates of initiation were remarkably similar to those recorded for first and second clutches at Delta Marsh (Table 1). Of the two cases at Delta Marsh in which first clutches also were initi- 
ated on 1 June (both in 1984) (Table 1), the second clutches were initiated on 30 June, one or two days earlier than those at Inuvik.

Initiation of the earliest clutches by Yellow Warblers in other populations nesting at the northern limit of the range-Churchill, Manitoba (Briskie 1995), Yukon (Sinclair et al. 2003), and Alaska (Kessel 1989) - has not been recorded before the middle of June. Briskie (1995, page 539), commenting on the length of the breeding season of the Yellow Warbler at Churchill, observed some clutches that were replaced after failure early in the season, but found "... no evidence of double-brooding and [stated that] it is unlikely to occur. In the average year, even the earliest nests do not fledge young before late July and any second brood would require birds to remain in the area well past the end of the short subarctic summer." The dynamics of breeding of this and other species at the northern limit of their range require additional study, especially when temperatures are increasing.

\section{Implications of double brooding}

The proportion of pairs with double broods recorded in the population in suitable years at Delta Marsh is not known but its determination was likely influenced, in the first instance, by the availability of marked pairs and, more importantly, by the number of marked individuals whose first nests managed to survive through fledging, where $\sim 60 \%$ of all nesting attempts by Yellow Warblers are depredated or fail due to inclement weather (Goossen and Sealy 1982; Guigueno and Sealy 2010). Probably no more than $5-10 \%$ of pairs attempted to rear second broods in the 5 years in which they were recorded, but double brooding also may have occurred in 4 additional years of the study $(1978,1980$ 82, see table III in Sealy 1995) that experienced similar nesting phenology. Nests tended by the marked pairs in those years may have failed before second clutches could be initiated, although if double brooding occurred, I should have recorded re-use of some first nests by unmarked pairs. Spring temperatures in 1979 and 1983 were lower and first clutches were not laid until 9 and 12 June, respectively (table III in Sealy 1995), probably too late for double brooding.

Within the limits of the small sample size of Yellow Warbler nests parasitized by Brown-headed Cowbirds (all of them second nests) (Table 1), it is noteworthy that parasitism was rejected at one of the four nests. Females tend to bury Brown-headed Cowbird eggs in the latter portion of the clutch-initiation season, but almost all females accept Brown-headed Cowbird eggs towards the end of the breeding season, when they are running out of time (Clark and Robertson 1981; Sealy 1995; Guigueno and Sealy 2010). This single instance of burial was unusual because it was initiated only two or three days before the last Yellow Warbler eggs of the season were laid at Delta Marsh in 1986 (table III in Sealy 1995).
Short-lived individuals (Klimkiewicz et al. 1983) might be expected to raise more than one brood in years when conditions are favourable (Evans Ogden and Stutchbury 1996), but they would have to be responsive to early spring temperatures. In a study of arrival and clutch initiation by Yellow Warblers over 30 years at Delta Marsh, Mazerolle et al. (2011) reported that individuals exhibited considerable plasticity in the dates of clutch initiation in response to mean May temperatures. This plasticity was observed only at the beginning of the breeding season, as Yellow Warblers molt and migrate early (Morton 1976) and arrive on the wintering grounds from Mexico south to Peru where they compete for feeding territories, as early as late August (Neudorf and Tarof 1998). Rigid scheduling of molt and migration may preclude attempts to rear second broods, except in early seasons, but this may become more frequent with increasing temperatures.

\section{Acknowledgements}

I thank J. Briskie, D. Busby, H. den Haan, J. Goossen, K. Hobson, D. MacKenzie, R. Olenick, G. (Biermann) Pohajdak, J. Porter, and G. Sutherland for assistance in the field during the early years of the research on songbirds at Delta Marsh, Manitoba, which included considerable assistance with banding and colourmarking. I thank an anonymous reviewer and Anna Drake for constructive comments offered during the review of the manuscript. In addition, I would like to thank Anna for allowing me to include the record of double brooding by a pair of Yellow Warblers at an even more northerly latitude and D. J. Green, M. Hepp, and S. P. Quinlan for providing data from a site near Revelstoke, British Columbia. This work was funded chiefly by the Natural Sciences and Engineering Research Council of Canada, augmented by substantial in-kind support provided by the Delta Marsh Field Station (University of Manitoba).

\section{Literature Cited}

Bancroft, J. 1979. Double-brooded Yellow Warbler? Blue Jay 37: 170-171.

Bolinger, E. K., and J. D. Maddox. 2000. A double-brooded Dickcissel. Prairie Naturalist 32: 253-255.

Briskie, J. V. 1995. Nesting biology of the Yellow Warbler at the northern limit of its range. Journal of Field Ornithology 66: 531-543.

Clark, K. L., and R. J. Robertson. 1981. Cowbird parasitism and evolution of anti-parasite strategies in the Yellow Warbler. Wilson Bulletin 93: 249-258.

Cosens, S. E., and S. G. Sealy. 1986. Age-related variation in song repertoire size and repertoire sharing of Yellow Warblers (Dendroica petechia). Canadian Journal of Zoology 64: 1926-1929.

Evans Ogden, L. J., and B. J. M. Stutchbury. 1996. Constraints on double brooding in a neotropical migrant, the Hooded Warbler. Condor 98: 736-744.

Gavin, T. A. 1984. Broodedness in Bobolinks. Auk 101: 179181. 
Gollop, J. B. 1979. Comments on the Whyewold Warbler. Blue Jay 37: 171-172.

Goossen, J. P., and S. G. Sealy. 1982. Production of young in a dense nesting population of Yellow Warblers, Dendroica petechia, in Manitoba. Canadian Field-Naturalist 96: 189199.

Guigueno, M. F., and S. G. Sealy. 2010. Clutch abandonment by parasitized Yellow Warblers: egg burial or nest desertion? Condor 112: 399-406.

Hobson, K. A., and S. G. Sealy. 1989. Mate guarding in the Yellow Warbler Dendroica petechia. Ornis Scandinavica 20: 241-249.

Holmes, R. T., T. W. Sherry, P. P. Marra, and K. W. Petit. 1992. Multiple brooding and productivity of a neotropical migrant, the Black-throated Blue Warbler (Dendroica caerulescens), in an unfragmented temperate forest. Auk 109: 321-333.

Kessel, B. 1989. Birds of the Seward Peninsula, Alaska. University of Alaska Press, Fairbanks, Alaska. 330 pages.

Klimkiewicz, B. K., R. B. Clapp, and A. G. Futcher. 1983. Longevity records of North American birds: Remizidae through Parulinae. Journal of Field Ornithology 54: 287 294.

MacKenzie, D. I. 1982. The dune-ridge forest, Delta Marsh, Manitoba: overstory vegetation and soil patterns. Canadian Field-Naturalist 96: 61-68.

MacKenzie, D. I., S. G. Sealy, and G. D. Sutherland. 1982. Nest-site characteristics of the avian community in the dune-ridge forest, Delta Marsh, Manitoba: a multivariate analysis. Canadian Journal of Zoology 60: 2212-2223.

Martin, T. E. 1987. Food as a limit on breeding birds: a life history perspective. Annual Review of Ecology and Systematics 18: 453-487.

Mazarolle, D. F., S. G. Sealy, and K. A. Hobson. 2011. Interannual flexibility in breeding phenology of a neotropical migrant songbird in response to weather conditions at breeding and wintering areas. Écoscience 18: 18-25.

Morton, E. S. 1976. The adaptive significance of dull plumage coloration in Yellow Warblers. Condor 78: 423.

Mulvihill, R. S., S. C. Latta, and F. C. Newell. 2009. Temporal constraints on the incidence of double brooding in the Louisiana Waterthrush. Condor 111: 341-348.
Neudorf, D. L., and S. A. Tarof. 1998. The role of chip calls in winter territoriality of Yellow Warblers. Journal of Field Ornithology 69: 30-36.

Pohajdak, G. C. 1988. Feeding guilds, diets and foraging behavior of insectivorous passerines in a riparian habitat in Manitoba. Ph.D. dissertation, University of Manitoba, Winnipeg. 220 pages.

Radabaugh, B. E. 1971. Double-broodedness in Kirtland's Warbler. Bird-Banding 43: 55.

Reid, M. L., and S. G. Sealy. 1986. Behavior of a polygynous yearling male Yellow Warbler. Wilson Bulletin 98: 315317

Salt, W. R. 1973. Alberta Vireos and Wood Warblers: Families Vireonidae and Parulidae-Distribution and Breeding. Publication No. 3. Provincial Museum and Archives of Alberta, Edmonton, Alberta. 141 pages.

Sealy, S. G. 1980a. Breeding biology of Orchard Orioles in a new population in Manitoba. Canadian Field-Naturalist 94: $154-158$

Sealy, S. G. 1980b. Reproductive responses of Northern Orioles to a changing food supply. Canadian Journal of Zoology 57: 221-227.

Sealy, S. G. 1984. Extra-pair copulation in the Yellow Warbler (Dendroica petechia). Animal Behaviour 32: 295-296.

Sealy, S. G. 1995. Burial of cowbird eggs by parasitized Yellow Warblers: an empirical and experimental study. Animal Behaviour 49: 877-889.

Sealy, S. G., and G. C. Biermann. 1983. Timing of breeding and migration in a population of Least Flycatchers in Manitoba. Journal of Field Ornithology 54: 113-122.

Sinclair, P. H., W. A. Nixon, C. D. Eckert, and N. L. Hughes. 2003. Birds of the Yukon Territory. UBC Press, Vancouver, British Columbia. 595 pages.

Snow, D. W. 1966. The annual cycle of the Yellow warbler in the Galapagos. Bird-Banding 37: 44-49.

Stewart, R. E. 1953. A life history of the yellow-throat. Wilson Bulletin 65: 99-115.

Stoner, D. 1932. Ornithology of the Oneida Lake region: with reference to the late spring and summer seasons. Roosevelt Wild Life Annals 2(3 and 4): 277-760.

Received 6 June 2013

Accepted 8 July 2013 